\title{
GAMBARAN KEMAMPUAN, LINGKUNGAN KERJA SOSIAL DAN KINERJA KARYAWAN
}

\author{
Desita Anggra Dewi \\ Universitas Pendidikan Indonesia \\ desitaanggradewi@student.upi.edu \\ Syamsul Hadi Senen \\ Universitas Pendidikan Indonesia \\ syamsulhadisenen@upi.edu \\ Masharyono \\ Universitas Pendidikan Indonesia \\ masharyono@upi.edu
}

\begin{abstract}
ABSTRAK
Tujuan - Tujuan penelitian ini adalah untuk mengetahui gambaran kemampuan, lingkungan kerja sosial dan kinerja.

Desain/metodologi/pendekatan - Desain penelitian ini adalah cross sectional. Penelitian ini menggunakan pendekatan deskriptif dengan metode explanatory survey. Unit analisis karyawan sebanyak 103 orang. Pengumpulan data dengan menggunakan kuesioner. Teknik analisis yang digunakan adalah teknik deskriptif dengan menggunakan distribusi frekuensi.

Temuan - Berdasarkan hasil penelitian menggunakan analisis deskriptif, didapatkan hasil bahwa kemampuan kerja berkategori sangat baik, lingkungan kerja sosial berkategori sangat kondusif, dan kinerja berkategori sangat tinggi.

Orisinalitas - Perbedaan dalam penelitian ini terletak pada objek penelitian, waktu penelitian, alat ukur, literatur yang digunakan, teori yang digunakan dan hasil penelitian.
\end{abstract}

Kata kunci : : Kemampuan, Lingkungan Kerja Sosial, Kinerja

Tipe artikel $\quad$ : Studi Kasus

\begin{abstract}
Purpose - The purpose of this study is to see the description of ability, social work environment, and performance.

The design / methodology / approach - The design of this study was cross sectional. This research uses descriptive approach with explanatory survey method. The employee analysis unit is 103 people. Data collection using questionnaire. The analysis technique used is descriptive technique by using frequency distribution

Findings - Based on the results of research using descriptive analysis, the results obtained that ability in the very good category, social work environment in the very conducive category, and performance in the high category.

Originality - This study provides a basis for understanding the issues of the ability and social work environment on performance. The difference of this research with previous research is on the object in PT. Indorama Synthetics Tbk. Polyester Division In Purwakarta, ability variable, social work environment and performance, and references used by researchers with previous researchers.
\end{abstract}

Keywords: Ability, Social Work Environment, Performance

Type of article: Research Paper

\section{PENDAHULUAN}

Sumber daya manusia sangat penting sebagai keunggulan organisasi dan bertindak sebagai faktor utama untuk mencapai tujuan organisasi (Muda, Rafiki, \& Harahap, 2014). Organisasi membutuhkan sumber daya manusia yang bisa bekerja secara efisien dan efektif bagi organisasi yang mampu mengambil alih pengelolaan karyawan dengan baik (Sumiyati, Masharyono, Purnama, \& Pratama, 2016). Sasaran utama 
pengelolaan sumber daya manusia adalah meningkatkan kinerja karyawan. Dengan kata lain, manajemen sumber daya manusia diharapkan bisa menghasilkan karyawan dengan memiliki kinerja yang tinggi (Siramiati $\mathrm{Ni}$ Wayan; Surachman, 2016).

Kinerja karyawan masih menjadi perhatian, karena kinerja merupakan inti dari permasalahan di manajemen sumber daya manusia (Schaefer et al, 2015). Rendahnya kinerja karyawan di era kompetitif ini masih menjadi masalah utama dalam manajemen sumber daya manusia (Senen, Sumiyati, Masharyono \& Triananda, 2016). Masalah kinerja karyawan dihadapi oleh perusahaan di berbagai sektor di banyak negara, baik yang bergerak di sektor publik dan swasta, di institusi kesehatan, pendidikan, perbankan, perusahaan milik negara, sampai perusahaan kecil (Senen, Sumiyati, Masharyono \& Triananda, 2016).

Kinerja karyawan sangat penting dalam upaya perusahaan untuk mencapai tujuannya dan menjadi salah satu faktor utama kesuksesan di perusahaan (Nuryanti \& Rahmawati, 2016). Rendahnya kinerja karyawan menjadi prioritas yang dihadapi oleh perusahaan, sehingga perusahaan tersebut memaksimalkan kinerja karyawannya yang menjadi tantangan utama bagi organisasi (Osa, 2014).

Kinerja bisa mempengaruhi berlangsungnya kegiatan suatu organisasi atau perusahaan, semakin baik kinerja yang ditunjukkan oleh para karyawan akan sangat membantu dalam perkembangan organisasi atau perusahaan tersebut (Wardhana, Tarmedi, \& Sumiyati, 2016). Baik buruknya kinerja individu tergantung pada pemahaman dan kemampuan untuk mencapai target sesuai kebenarannya (Khan et al, 2016). Kinerja karyawan dilihat dari segi produktivitas dan output karyawan yang mempengaruhi serta membantu organisasi agar bekerja secara efektif dan efisien dalam mencapai tujuannya (Emelia \& Darko, 2017).

Sebuah penelitian yang dilakukan oleh Odunlami \& Matthew, (2014) mengenai kinerja karyawan di industri manufaktur menyatakan bahwa karyawan merupakan bagian yang tidak dapat terpisahkan dari manajemen sumber daya manusia. Hal ini diperkuat oleh penelitian Emeka, Ifeoma, \& Emmanuel, (2015) menyatakan bahwa sektor manufaktur di perusahaan Nigeria tercatat sebagai salah satu mesin pertumbuhan dalam pekerjaan yang dapat menciptakan kekayaan untuk pembangunan, akan tetapi sektor ini tidak mampu mengatasi tantangan yang tercermin dari kinerjanya yang buruk selama bertahun-tahun. Permasalahan karyawan dengan tingkat kinerja rendah pada industri manufaktur terindikasi pada kemampuan menguasai peralatan yang rendah dan karyawan yang tidak menyelesaikan pekerjaan secara tepat waktu (García-Pinillos et al, 2015).

Perusahaan yang bergerak dalam sektor manufaktur merupakan perusahaan yang bergerak dalam sektor produksi yang sangat bertumpu pada efisiensi dan keefektifan kerja karyawan. Oleh karena itu perusahaan yang bergerak pada sektor manufaktur sangat mengandalkan kualitas dan kinerja karyawan yang tinggi (Syamsul Hadi Senen \& Wahyuni, 2016:59). Berdasarkan penelitian yang dilakukan oleh Supriyani \& Mahmud, (2013) mengenai kinerja karyawan di industri manufaktur, disimpulkan bahwa turunnya kinerja karyawan ditunjukan oleh banyaknya karyawan yang absen, target hasil produksi dan terlambat datang ke tempat kerja.

Ada beberapa faktor yang mempengaruhi kinerja karyawan seperti kualitas kerja, keterampilan, Responsif, kecepatan, inisiatif, kemampuan, komunikasi (Torang, 2012). Berbeda dengan Faktor penting penentu kinerja karyawan dan keterlibatan mereka di tempat kerja adalah struktur gaji, kurangnya kesempatan, skema insentif yang lemah, kode promosi berdasarkan senioritas, penundaan dalam promosi, dan tidak adanya strategi motivasi (Assan, 2015; Zheng dan Lamond, 2010). Sedangkan Tran \& Thao, (2015) faktor yang mempengaruhi kinerja karyawan adalah: kepemimpinan, coaching, pemberdayaan, partisipasi, budaya organisasi, lingkungan kerja sosial, motivasi, dan pelatihan. Berdasarkan faktor-faktor tersebut, yang dilakukan maka diambil beberapa solusi untuk meningkatkan kepuasan kerja karyawan yaitu dengan pelatihan, dan pemberdayaan.

Upaya peningkatkan kinerja, diantaranya dengan memperhatikan kemampuan seorang karyawan yang dapat berpengaruh terhadap kinerja karyawan. Salah satu bentuk kemampuan yang diyakini dapat memainkan peranan yang sangat penting bagi suatu perusahaan untuk meningkatkan kinerja karyawannya adalah kemampuan (Burns R. B, 2012:148). Kinerja dapat ditingkatkan dengan menggunakan kemampuan untuk menghasilkan gagasan baru untuk membangun hubungan dan proses kerja (Sajid, 2017). Masalah kinerja karyawan terjadi karena pengetahan dan keahlian antar karyawan memiliki gap sehingga pekerjaan tidak dapat selesai tepat waktu (Chen, S., Zhu, X., Welk, G. J., Kim, Y., Lee, J., \& Meier, 2014).

Selain kemampuan yang dapat mempengaruhi kinerja karyawan dengan memperhatikan lingkungan kerja. Lingkungan kerja yang dapat menunjang kelancaran, keamanan, keselamatan, kebersihan, serta kenyamanan dalam bekerja dan adanya fasilitas yang memadai, sehingga 
karyawan merasa aman, tenang dan senang dalam menjalankan tugas-tugas yang dibebankan dan menjadi tanggung jawabnya (Mahardikawanto, 2013; Suprayitno, 2007:24). Lingkungan kerja memberikan dampak besar kepada karyawan, baik terhadap hasil negatif atau hasil positif (Mathews \& Khann, 2016; Chandrasekar, 2001).

Lingkungan kerja terbagi menjadi dua jenis, yaitu lingkungan kerja fisik dan sosial (Sedarmayanti, 2007; Diah Indriani Suwondo, 2015). Lingkungan kerja sosial memainkan peran penting dalam proses produksi yang dilakukan oleh karyawan atau karyawan di semua tingkat manajemen dalam rangka meningkatkan kinerja karyawan (Sumiyati, Masharyono, Purnama, \& Pratama, 2016). Seorang karyawan bekerja di dalam perusahaan tidak sendiri, pasti membutuhkan orang lain. Dengan demikian, karyawan perlu membina hubungan yang baik antara rekan kerja, bawahan maupun atasan. Temuan penelitian telah menetapkan bahwa peningkatan kinerja di tempat kerja disebabkan bukan hanya dengan pelatihan, namun juga oleh pengaruh organisasi lainnya, yang berada di luar kendali pelatihan, misalnya perilaku manajer lini, imbalan dan insentif, praktik perekrutan, lingkungan kerja, peralatan dan sejumlah aspek budaya lainnya yang mempengaruhi kinerja di tempat kerja (Anthony, 2017).

Berdasarkan latar belakang masalah di atas, maka tujuan penelitian ini adalah untuk memperoleh hasil temuan mengenai: (1) gambaran kemampuan, (2) gambaran lingkungan kerja sosial, (3) gambaran kinerja.

\section{KAJIAN PUSTAKA}

Manajemen sumber daya manusia (MSDM) dapat diartikan sebagai ilmu dan seni yang mengatur hubungan dan peranan tenaga kerja agar efektif dan efisien dalam penggunaan kemampuan manusia agar dapat mencapai tujuan di setiap perusahaan (Mathis \& Jackson, 2011). Organisasi membutuhkan sumber daya manusia yang bisa bekerja secara efisien dan efektif bagi organisasi yang mampu mengambil alih pengelolaan karyawan dengan baik (Sumiyati, Masharyono, Purnama, \& Pratama, 2016). Manajemen sumber daya manusia berguna untuk meningkatkan kontribusi produktif orang-orang yang ada di dalam perusahaan melalui sejumlah cara yang bertanggung jawab secara strategis, etis dan sosial (Rivai \& Sagala, 2013).

One of resources which is the most important assets organization is human resources (1), because human resources plays a role in achieving the objective organization (2). Human resources is the factor dynamic forward capable of determining or the withdrawal of an organization, yang menyatakan bahwa salah satu asset terpenting dalam organisasi yaitu sumber daya manusia, Karena sumber daya manusia berperan dalam pencapaian organisasi. Salah satu sumber daya yang merupakan aset terpenting organisasi adalah sumber daya manusia karena sumber daya manusia berperan dalam mencapai tujuan organisasi (Masharyono, Sumiyati, 2016).

Mathis \& Jackson, (2011:6) mengemukakan tujuh fungsi dari manajemen sumber daya manusia yaitu 1) Strategic HR Management, 2) Equal Employment Opportunity, 3) Staffing, 4) Talent Management and Development, 5) Total Rewards, 6) Risk Management and Worker Protection 7), Employee and Labor Relations.

Berdasarkan pada fungsi sumber daya manusia tersebut terdapat fungsi talent management berfokus pada individu yang siap untuk mendapatkan pekerjaan saat dibutuhkan, dan orang-orang yang berbakat yang sedang dikembangkan untuk kebutuhan organisasi di masa depan (Mathis \& Jackson, 2011). Salah satu cara untuk meningkatkan talent management dengan merekrut dan menyeleksi karyawan melalui pelatihan, perencanaan suksesi, perencanaan karir, pengembangan, dan manajemen kinerja (Mathis \& Jackson, 2011).

Pelatihan berupaya sebagai kesuksesan bisnis dan menjadikan suatu organisasi untuk melakukan perbaikan terus-menerus agar menghasilkan output yang telah direncanakan. Dengan pelatihan terus-menerus, organisasi akan memiliki karyawan dengan pengetahuan, keterampilan, dan kemampuan yang dibutuhkan untuk bersaing secara efektif (Mathis \& Jackson, 2011). Dalam fungsi manajemen sumber daya manusia kemampuan kerja memiliki peranan menjadi salah satu faktor yang menunjang tercapainya visi dan misi organisasi untuk berkembang (Kumar, 2016). Suatu perusahaan akan berhasil atau bahkan gagal sebagian besar ditentukan oleh kemampuannya (Thoha, 2010:10). Kemampuan dapat membangkitkan karyawan, sehingga dapat berkembang dan pencapaian kinerjanya dapat melebihi apa yang diperkirakan perusahaan, selain itu kemampuan dianggap efektif dalam situasi dan budaya apapun (Yukl, 2010).

Kemampuan (Ability) merupakan potensi yang ada dalam diri seseorang untuk berbuat sehingga memungkinkan seseorang untuk dapat melakukan pekerjaan ataupun tidak dapat melakukan pekerjaan tersebut. Salah satu faktor yang sangat penting dan berpengaruh terhadap keberhasilan karyawan di dalam melaksanakan suatu pekerjaan adalah kemampuan kerja (Bolli, T., \& Farsi, 2015). Setiap jenis pekerjaan menuntut pengetahuan, keterampilan dan sikap tertentu agar dapat melaksanakan tugas tersebut dengan baik. Agar pekerjaan terlaksana dengan 
efektif atau berkinerja prima di tempat kerja pada situasi tertentu (Moeheriono, 2010:2).

Pada teori Sutermeister, (1976) bahwa kemampuan menunjukan potensi orang atau karyawan untuk melaksanakan tugas atau pekerjaan yang mana setiap jenis pekerjaan menuntut pengetahuan, keterampilan dan sikap tertentu agar dapat melaksanakan tugas tersebut dengan baik serta kemampuan menekankan pengertian sebagai hasil atau apa yang keluar (outcomes) dari sebuah pekerjaan dan kontribusi mereka pada organisasi.

Kemampuan kerja yaitu mencerminkan keseimbangan antara kapasitas individu, mental dan tuntutan pekerjaan (Joaquin Calatayud et,al 2015). Senada dengan pernyataan Robbins, Stephen P \& Judge, (2013) kemampuan merupakan suatu kapasitas individu untuk mengerjakan berbagai tugas dalam suatu pekerjaan. Karakteristik kemampuan menurut Robbins, Stephen P \& Judge, (2013) seperti kemampuan intelektual (intellectual ability) dan kemampuan fisik (intellectual physical). Dimensi kemampuan menurut Sutermeister, (1976), yaitu 1) knowledge (pengetahuan) yang didasari oleh pendidikan, pengalaman, latihan dan minat, dan 2) skills (keahlian) yang terdiri dari kecakapan (attitude) dan kepribadian (personality).

Kemampuan kerja dipengaruhi oleh beberapa faktor, menurut (Brasileira et al, 2014) mengatakan faktor-faktor yang mempengaruhi kemampuan sebagai berikut: 1) Disfungsi membatasi kemampuan mereka untuk bekerja; 2) Pekerja lanjut usia dan perempuan menunjukkan hubungan terbalik dengan hilangnya produktivitas di tempat kerja; 3 ) Tingkat pendidikan, partisipasi dalam kegiatan; 4) Tuntutan mental dan fisik dalam melakukan pekerjaan.

Berdasarkan pada fungsi sumber daya manusia terdapat fungsi risk management yang efektif merupakan komponen dalam manajemen sumber daya manusia. Ruang lingkup dari manajemen risiko terdiri dari keselamatan, kesehatan dan keamanan di tempat kerja (Mathis \& Jackson, 2011). Pendekatan untuk menciptakan lingkungan kerja yang aman dan nyaman berkaitan dengan program safety, health \& wellbeing (Andresen, M., \& Nowak, 2015). Mathis \& Jackson, (2011), mengatakan bahwa ergonomi adalah studi dan desain dari lingkungan kerja.

Lingkungan kerja terbagi menjadi dua jenis, yaitu lingkungan kerja fisik dan sosial (Sedarmayanti, 2007; Diah Indriani Suwondo, 2015). Lingkungan kerja sosial merupakan keadaan yang terjadi dan berkaitan dengan hubungan kerja, baik hubungan dengan atasan, hubungan dengan sesama rekan kerja maupun pelayanan kepada masyarakat (Sedarmayanti, 2011). Sesuatu yang berhubungan dengan segi psikis dari lingkungan kerja disebut sebagai lingkungan kerja sosial (Mondy \& Martocchio, 2016). Lingkungan kerja sosial memainkan peran penting dalam proses produksi yang dilakukan oleh karyawan atau karyawan di semua tingkat manajemen dalam rangka meningkatkan kinerja karyawan (Sumiyati et al., 2016).

Menurut Nitisemito, (2003:183) perusahan hendaknya dapat mencerminkan kondisi yang mendukung kerja sama antara tingkat atasan, bawahan maupun yang memiliki status jabatan yang sama di perusahaan. Kondisi yang hendaknya diciptakan adalah suasana kekeluargaan, komunikasi yang baik dan pengendalian diri. Membina hubungan yang baik antara sesama rekan kerja, bawahan maupun atasan harus dilakukan karena kita saling membutuhkan. Hubungan kerja yang terbentuk sangat mempengaruhi psikologis karyawan.

Lingkungan kondusif bisa tercipta jika adanya komunikasi yang baik dalam lingkungan perusahaan, interaksi antar karyawan, motivasi kerja tinggi, tidak ada saling curiga, dan memberikan kontribusi menjadi orientasi setiap karyawan (Bagus Kisworo, 2012:64). Pendapat lain dikemukakan oleh Sedarmayanti, (2011:46) menjelaskan bahwa lingkungan kerja sosial terbetuk oleh dua dimensi yaitu, hubungan kerja dengan atasan dan hubungan kerja dengan sesama rekan kerja. Sedangkan menurut Sunyoto, (2012:44), hubungan rekan kerja dalam lingkungan kerja non fisik dibagi menjadi dua, yaitu hubungan individu dan hubungan kelompok.

Menurut Sedarmayanti dalam Wulan (2011:21) bahwa faktor-faktor yang mempengaruhi lingkungan kerja sosial diantaranya, 1) struktur kerja, 2) tanggung jawab kerja, 3) perhatian dan dukungan pemimpin, 4) kerja sama antar kelompok, 5) kelancaran komunikasi.

Berdasarkan pada fungsi sumber daya manusia tersebut terdapat fungsi talent management and development yang merupakan proses menetapkan standar kinerja dan mengevaluasi kinerja yang bertujuan untuk mengetahui hasil kerja baik kualitas maupun kuantitas yang dihasilkan karyawan atau perilaku nyata dalam pekerjaannya (Mathis \& Jackson, 2011).

Kinerja merupakan perilaku nyata yang ditampilkan oleh setiap individu sebagai prestasi kerja yang dihasilkan oleh karyawan sesuai dengan perannya dalam perusahaan (Rivai, Veitzhal, \& Sagala, 2014). Wibowo, (2014:62) memandang kinerja sebagai cara untuk memastikan bahwa pekerja individual atau tim tahu apa yang diharapkan dan mereka tetap fokus 
pada kinerja efektif dengan memberikan perhatian pada tujuan, ukuran, dan penilai.

Menurut Albrecht et al, (2012) kinerja adalah suatu hasil kerja yang dicapai seseorang dalam melaksanakan tugas-tugas yang dibebankan kepadanya atas dasar pengalaman, kesungguhan serta pengukuran. Indikator kinerja digunakan untuk aktivitas dasar perilaku yang dapat diamati dengan lebih mengutamakan menggunakan sudut pandang harapan kedepan dari pada melihat kearah belakang. Perusahaan memiliki 9 standar penilaian untuk mengukur kinerja karyawan berdasarkan: 1) Tanggung jawab, 2) Inisiatif, 3) Kerjasama, 4) Etika \& komunikasi, 5) Disiplin \& kehadiran, 6) Pengetahuan mengenai pekerjaan, 7) kualitas pekerjaan, 8) kecepatan kerja, dan 9) kerapihan.

Adapun indikator kinerja karyawan menurut Gomez-Mejia, (2012) terdapat lima indikator kinerja, yaitu: 1) Quality of work, 2) Quantity of work performance, 3) Interpersonal effectiveness, 4) Competencies, 5) Job Knowledge. Kinerja karyawan dapat diukur melalui 1) Ketepatan waktu, 2) Ketercapaian target, 3) Pemahaman pekerjaan, 4) Pemahaman standar oprasional, 5) Penyampaian ide dan gagasan, 6) Kerjasama, 7) Tanggungjawab, 8) Cara kepemimpinan (Zachary, 2017).

Berdasarkan penjelasan mengenai gambaran kemampuan, lingkungan kerja sosial dan kinerja karyawan, maka disusun sebuah paradigma analisis kemampuan, lingkungan kerja sosial dan kinerja karyawan secara jelas digambarkan dalam Gambar 1 sebagai berikut:

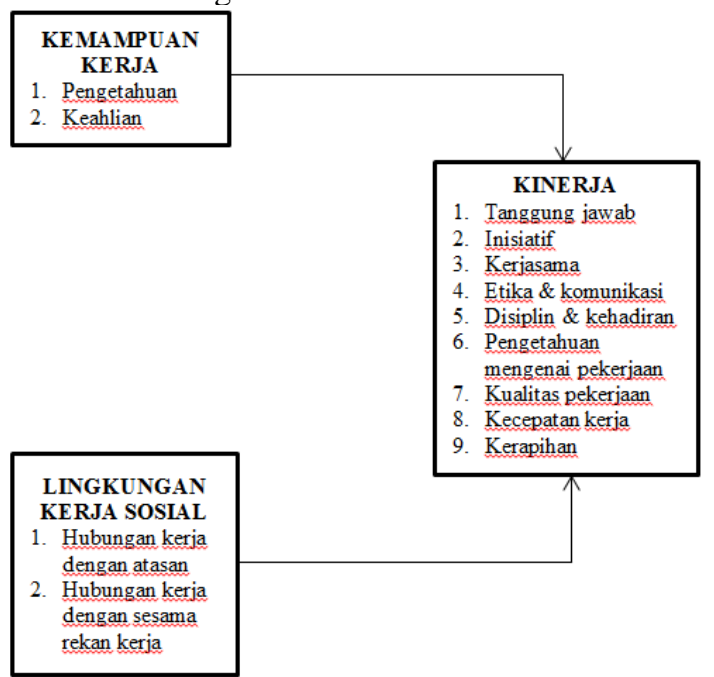

\section{GAMBAR 1 PARADIGMA PENELITIAN}

\section{METODE PENELITIAN}

Penelitian ini dilakukan untuk mengatahui gambaran kemampuan, lingkungan kerja sosial dan kinerja karyawan PT. Indorama Synthetics Tbk. Polyester Division di Purwakarta. Adapun yang menjadi objek penelitian sebagai variabel $\mathrm{X}$ atau variabel bebas (independent variabel) adalah kemampuan kerja dengan dimensinya yang mencakup pengetahuan (knowledge) dan keahlian (skill). Serta lingkungan kerja sosial dengan dimensinya yang mencakup hubungan kerja dengan atasan dan hubungan kerja dengan sesama rekan kerja.

Masalah penelitian yang merupakan variabel (Y) atau variabel terikat (dependent variabel) adalah kinerja karyawan dengan indikatornya 1) Tanggung jawab, 2) Inisiatif, 3) Kerjasama, 4) Etika \& komunikasi, 5) Disiplin \& kehadiran, 6) Pengetahuan mengenai pekerjaan, 7) kualitas pekerjaan, 8) kecepatan kerja, dan 9) kerapihan.

Penelitian ini dilakukan di PT. Indorama Synthetics Tbk. Polyester Division yang berlokasi di Jl. Industri Ubrug, Purwakarta, Jawa Barat.. Adapun yang menjadi objek penelitian ini adalah tanggapan responden tentang kemampuan dan lingkungan kerja sosial terhadap kinerja karyawan Sedangkan yang menjadi unit analisis adalah karyawan PT. Indorama Synthetics Tbk. Polyester Division di Purwakarta. Penelitian ini dilakukan dalam kurun waktu kurang dari satu tahun, maka pendekatan yang digunakan adalah metode cross sectional method, dimana penelitian ini dengan cara mempelajari objek dalam kurun waktu tertentu atau tidak berkesinambungan dalam jangka waktu panjang.

Berdasarkan tingkat penjelasan dan bidang penelitian, maka jenis penelitian ini adalah penelitian deskriptif dan verifikatif, dengan metode penelitian yang digunakan adalah explonatory survey. Populasi dalam penelitian ini adalah karyawan PT. Indorama Synthetics Tbk. Polyester Division di Purwakarta yang berjumlah 103 orang.

Teknik pengumpulan data yang digunakan adalah studi kepustakaan, studi lapangan dengan penyebaran kuesioner secara langsung, dan studi literatur. Penelitian ini menggunakan teknik sampel jenuh, yaitu dengan mengambil seluruh jumlah karyawan PT. Indorama Synthetics Tbk. Polyester Division di Purwakarta sebanyak 103 orang.

\section{HASIL DAN PEMBAHASAN}

Kemampuan kerja adalah suatu kapasitas individu untuk mengerjakan tugas dan kondisi siap menerima segala situasi dan resiko yang akan dihadapi (Robbins, Stephen P \& Judge, 2013). Kemampuan (Ability) merupakan potensi yang ada dalam diri seseorang untuk berbuat sehingga memungkinkan seseorang untuk dapat melakukan pekerjaan ataupun tidak dapat melakukan pekerjaan tersebut. Salah satu faktor yang sangat penting dan berpengaruh terhadap keberhasilan karyawan di dalam melaksanakan 
suatu pekerjaan adalah kemampuan kerja (Bolli, T., \& Farsi, 2015).

Pada teori Sutermeister, (1976) bahwa kemampuan menunjukan potensi orang atau karyawan untuk melaksanakan tugas atau pekerjaan yang mana setiap jenis pekerjaan menuntut pengetahuan, keterampilan dan sikap tertentu agar dapat melaksanakan tugas tersebut dengan baik serta kemampuan menekankan pengertian sebagai hasil atau apa yang keluar (outcomes) dari sebuah pekerjaan dan kontribusi mereka pada organisasi. Dalam kemampuan terdapat 2 dimensi menurut Sutermeister, (1976) yaitu 1) knowledge (pengetahuan), 2) skills (keahlian).

Pengetahuan didasari oleh pendidikan, pengalaman, latihan dan minat. Keahlian (skill) terdiri dari kecakapan (attitude) dan kepribadian (personality). Kemampuan kerja yang baik akan meningkatkan kesejahteraan dan mendukung keberhasilan kerja. Pembahasan mengenai kemampuan sangat tinggi kaitannya dengan sikap profesionalisme dari cara kerja pegawai, yaitu kemampuan menguasi, memahami dan melaksanakan tugas yang sesuai dengan profesinya, mampu bekerja secara produktif, efisien, mandiri, inovatif juga memiliki dedikasi dan moral yang tinggi (Saari, L. M., \& Judge, 2014).

Berdasarkan hasil pengolahan data yang dilakukan melalui penyebaran angket pada karyawan PT. Indorama Synthetics Tbk. Polyester Division di Purwakarta, kemampuan dapat diukur melalui perhitungan rata-rata dimensi dan perhitungan skor keseluruhan. Berikut ini dipaparkan hasil dari rekapitulasi perhitungan skor:

\section{TABEL 1}

REKAPITULASI DIMENSI KEMAMPUAN

\begin{tabular}{clccc}
\hline No & Dimensi & Total Skor & Skor Ideal & \% \\
\hline 1 & Pengetahuan & 5181 & 6489 & $80 \%$ \\
2 & Keahlian & 3564 & 4326 & $82 \%$ \\
\hline & Total & $\mathbf{8 7 3 7}$ & $\mathbf{1 0 8 1 5}$ & $\mathbf{8 1 \%}$
\end{tabular}

Berdasarkan Tabel 1 aspek kemampuan paling tinggi yaitu terdapat pada dimensi skill (keahlian) memperoleh skor sebanyak 3564 atau 82\%, sementara dimensi paling rendah yaitu pada knowledge (pengetahuan) memperoleh skor 5181 atau $80 \%$. Secara keseluruhan variabel kemampuan memperoleh skor 8737, apabila di persentasekan kedalam skor ideal maka diperoleh persentase sebesar $81 \%$, dapat dikatakan menurut Muhammad Ali, (2013:184) bahwa hampir seluruh responden menyatakan kemampuan pada karyawan PT. Indorama Synthetics Tbk. Polyester Division di Purwakarta dalam kategori sangat baik. Sedangkan dilihat dari garis kontinum yang telah dihitung adalah:

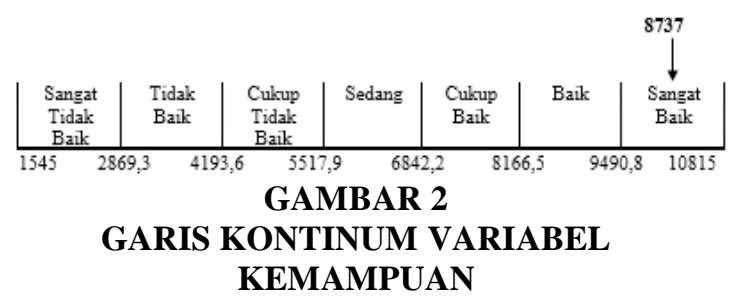

Berdasarkan Gambar 2 pada nilai kontinum variabel kemampuan yaitu 8737 sesuai dengan data penelitian yaitu termasuk kedalam kategori sangat baik, dengan demikian dapat dikatakan bahwa karyawan memiliki kemampuan yang sangat baik dijalankan pada perusahaan, akan tetapi pelatihan pada perusahaan masih perlu ditingkatkan karena semua dimensi berada di bawah skor ideal.

Berdasarkan hasil penelitian dari angket yang disebar kepada 103 responden diketahui bahwa kemampuan karyawan PT. Indorama Synthetics Tbk. Polyester Division di Purwakarta mencapai skor 8737 dari skor kriterium atau jumlah maksimal perolehan nilai responden terletak pada daerah 9490,8-10815 sehingga dapat dikatakan bahwa dalam penelitian ini kemampuan karyawan PT. Indorama Synthetics Tbk. Polyester Division di Purwakarta sangat baik, namun kemampuan tersebut perlu ditingkatkan lagi karena semua dimensi berada dibawah skor ideal.

Lingkungan kerja sosial merupakan keadaan yang terjadi dan berkaitan dengan hubungan kerja, baik hubungan dengan atasan, hubungan dengan sesama rekan kerja maupun pelayanan kepada masyarakat (Sedarmayanti, 2011). Sesuatu yang berhubungan dengan segi psikis dari lingkungan kerja disebut sebagai lingkungan kerja sosial (Mondy, R. W., \& Martocchio, 2016). Lingkungan kerja sosial sangat berpengaruh terhadap kerja pekerja dalam latar belakang keluarga pekerja (Sigit, 2003:183). Memperbaiki lingkungan kerja sosial akan meningkatkan kemungkinan karyawan untuk berkomitmen terhadap organisasi dan menjadikan perusahaan sebagai tempat kerja terbaik untuk bekerja (Armstrong \& Taylor, 2014). Dimensi pemberdayaan menurut Sedarmayanti (2011:46) yaitu hubungan kerja dengan atasan dan hubungan kerja dengan sesama rekan kerja.

Hubungan kerja dengan atasan merupakan Sikap atasan terhadap bawahan memberikan pengaruh bagi karyawan dalam melaksanakan aktivitasnya sikap yang bersahabat, saling menghormati dan menghargai perlu dalam hubungan antar karyawan dengan pimpinan untuk kerjasama dalam mencapai tujuan perusahaan. Sikap bersahabat yang diciptakan atasan akan menjadikan karyawan lebih betah untuk bekerja dan dapat menimbulkan semangat kerja bagi karyawan. 
Hubungan kerja dengan sesama rekan kerja merupakan Hubungan kerja antar karyawan sangat diperlukan untuk melakukan pekerjaan, terutama bagi karyawan yang bekerja secara kelompok. Apabila terjadi konflik maka akan memperkeruh suasana kerja dan akan menurunkan semangat kerja karyawan. Hubungan kerja yang baik antara karyawan yang satu dengan karyawan yang lainnya maka akan meningkatkan semangat kerja bagi karyawan, di mana mereka saling kerjasama atau saling membantu dalam menyelesaikan suatu pekerjaan.

Berdasarkan hasil pengolahan data yang dilakukan melalui penyebaran angket pada karyawan PT. Indorama Synthetics Tbk. Polyester Division di Purwakarta, lingkungan kerja sosial dapat diukur melalui perhitungan rata-rata dimensi dan perhitungan skor keseluruhan. Berikut ini dipaparkan hasil dari rekapitulasi perhitungan skor:

TABEL 2

REKAPITULASI DIMENSI LINGKUNGAN KERJA SOSIAL

\begin{tabular}{clccc}
\hline No & Dimensi & $\begin{array}{c}\text { Total } \\
\text { Skor }\end{array}$ & $\begin{array}{c}\text { Skor } \\
\text { Ideal }\end{array}$ & \% \\
\hline 1 & $\begin{array}{l}\text { Hubungan kerja } \\
\text { dengan atasan }\end{array}$ & 2618 & 3605 & $73 \%$ \\
2 & $\begin{array}{l}\text { Hubungan kerja } \\
\text { dengan sesame } \\
\text { rekan kerja }\end{array}$ & 2884 & 3605 & $80 \%$ \\
\hline & Total & $\mathbf{5 5 0 2}$ & $\mathbf{7 2 1 0}$ & $\mathbf{7 6 \%}$ \\
\hline
\end{tabular}

Berdasarkan Tabel 2 aspek lingkungan kerja sosial paling tinggi yaitu terdapat pada dimensi hubungan kerja dengan sesama rekan kerja memperoleh skor sebanyak 2884 atau $80 \%$, sementara dimensi paling rendah yaitu pada hubungan kerja dengan atasan dan memperoleh skor 2618 atau 73\%. Secara keseluruhan variabel lingkungan kerja sosial memperoleh skor 5502, apabila di persentasekan kedalam skor ideal maka diperoleh persentase sebesar 76\%, dapat dikatakan menurut Muhammad Ali, (2013:184) bahwa hampir seluruh responden menyatakan lingkungan kerja sosial pada karyawan PT. Indorama Synthetics Tbk. Polyester Division di Purwakarta dalam kategori sangat kondusif. Sedangkan dilihat dari garis kontinum yang telah dihitung adalah:

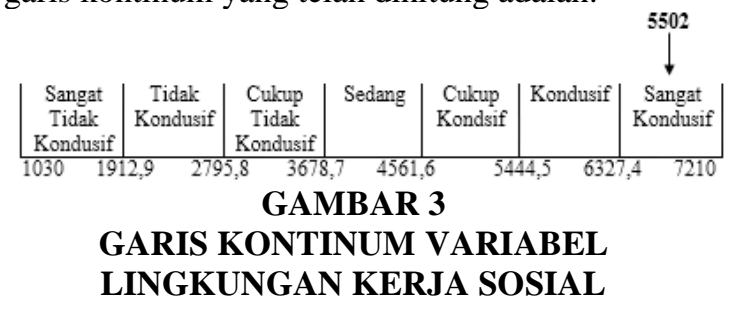

Berdasarkan Gambar 3 pada nilai kontinum variabel pelatihan yaitu 5502 sesuai dengan data penelitian yaitu termasuk kedalam kategori sangat kondusif, dengan demikian dapat dikatakan bahwa karyawan memiliki lingkungan kerja sosial yang kondusif dalam perusahaan, akan tetapi lingkungan kerja sosial pada perusahaan masih perlu ditingkatkan karena semua dimensi berada di bawah skor ideal.

Berdasarkan hasil penelitian dari angket yang disebar kepada 103 responden diketahui bahwa lingkungan kerja sosial karyawan PT. Indorama Sycnthetics Tbk. Polyester Division di Purwakarta mencapai skor 5502 dari skor kriterium atau jumlah maksimal perolehan nilai responden terletak pada daerah 6327,4-7210 sehingga dapat dikatakan bahwa dalam penelitian ini lingkungan kerja sosial pada karyawan PT. Indorama Synthetics Tbk. Polyester Division di Purwakarta sangat kondusif, namun lingkungan kerja sosial tersebut perlu ditingkatkan lagi karena semua dimensi berada dibawah skor ideal.

Organisasi membutuhkan sumber daya manusia yang bisa bekerja secara efisien dan efektif bagi organisasi yang mampu mengambil alih pengelolaan karyawan dengan baik (Sumiyati, Masharyono, Purnama, Pratama, 2016:649). Sasaran utama pengelolaan sumber daya manusia adalah meningkatkan kinerja karyawan. Dengan kata lain, manajemen sumber daya manusia diharapkan bisa menghasilkan karyawan dengan memiliki kinerja yang tinggi (Siramiati Ni Wayan; Surachman, 2016).

Kinerja meliputi hasil kerja baik kualitas maupun kuantitas yang dihasilkan karyawan atau perilaku nyata yang ditampilkan sesuai dengan tanggung jawab yang diberikan kepadanya (Aprilia \& Hudiwinarsih, 2012). Kinerja bisa mempengaruhi berlangsungnya kegiatan suatu organisasi perusahaan, semakin baik kinerja yang ditunjukkan oleh para karyawan akan sangat membantu dalam perkembangan organisasi atau perusahaan tersebut (Wardhana, Tarmedi, \& Sumiyati, 2016).

Kinerja berlandaskan peluang dalam kesuksesan sebuah organisasi karena kinerja berorientasi pada waktu bagaimana karyawan dapat berfungsi melaksanakan tugas yang dibebankan (Jyoti, J., \& Dev, 2016). Kinerja karyawan berarti konstruksi yang paling penting dalam bidang psikologi organisasi dan menejemen sumber daya manusia serta suatu usaha yang dilakukan dalam rangka mencapai prestasi yang lebih baik (Tummers, 2017). Sedangkan menurut (Rivai, Veitzhal, \& Sagala, 2014) mengungkapkan bahwa kinerja merupakan perilaku nyata yang ditampilkan oleh setiap individu sebagai prestasi kerja yang dihasilkan oleh karyawan sesuai dengan perannya dalam perusahaan. Perusahaan memiliki 9 standar penilaian untuk mengukur kinerja karyawan berdasarkan: 1) Tanggung jawab, 2) Inisiatif, 3) Kerjasama, 4) Etika \& komunikasi, 5) Disiplin \& 
kehadiran, 6) Pengetahuan mengenai pekerjaan, 7) kualitas pekerjaan, 8) kecepatan kerja, dan 9) kerapihan.

Berdasarkan hasil pengolahan data yang dilakukan melalui penyebaran angket pada karyawan PT. Indorama Synthetics Tbk. Polyester Division di Purwakarta, kinerja dapat diukur melalui perhitungan rata-rata dimensi dan perhitungan skor keseluruhan. Berikut ini dipaparkan hasil dari rekapitulasi perhitungan skor

TABEL 3

TABEL REKAPITULASI DIMENSI KINERJA

\begin{tabular}{|c|c|c|c|c|}
\hline No & Dimensi & $\begin{array}{l}\text { Total } \\
\text { Skor }\end{array}$ & $\begin{array}{l}\text { Skor } \\
\text { Ideal }\end{array}$ & $\%$ \\
\hline 1 & Tanggung jawab & 2345 & 2884 & $81 \%$ \\
\hline 2 & Inisiatif & 2264 & 2884 & $79 \%$ \\
\hline 3 & Kerjasama & 2380 & 2884 & $83 \%$ \\
\hline 4 & Etika\&Komunikasi & 1853 & 2163 & $86 \%$ \\
\hline 5 & Disiplin\&Kehadiran & 1792 & 2163 & $83 \%$ \\
\hline 6 & $\begin{array}{l}\text { Pengetahuan } \\
\text { mengenai pekerjaan }\end{array}$ & 1735 & 2163 & $80 \%$ \\
\hline 7 & Kualitas pekerjaan & 1808 & 2163 & $84 \%$ \\
\hline 8 & Kecepatan kerja & 1737 & 2163 & $80 \%$ \\
\hline 9 & Kerapihan & 1226 & 1442 & $85 \%$ \\
\hline & Total & 17176 & 20909 & $82 \%$ \\
\hline
\end{tabular}

Berdasarkan Tabel 3 aspek kinerja paling tinggi yaitu terdapat pada dimensi etika dan komunikasi memperoleh skor sebanyak 1853 atau $86 \%$, sementara dimensi paling rendah yaitu pada inisiatif memperoleh skor 2264 atau $76 \%$. Secara keseluruhan variabel kepuasan kerja memperoleh skor 17176, apabila di persentasekan kedalam skor ideal maka diperoleh persentase sebesar 82\%, dapat dikatakan menurut Muhammad Ali, (2013:184) bahwa hampir seluruh responden menyatakan kinerja pada karyawan PT. Indorama Synthetics Tbk. Polyester Division di Purwakarta dalam kategori sangat tinggi. Sedangkan dilihat dari garis kontinum yang telah dihitung adalah:

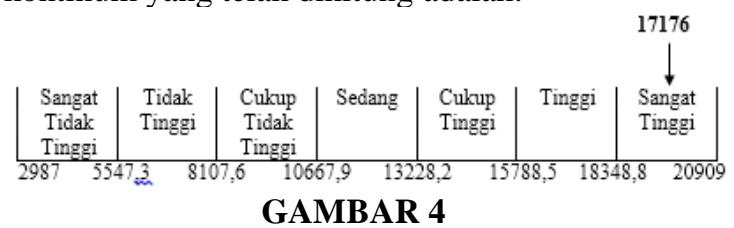

\section{GARIS KONTINUM VARIABEL KINERJA}

Berdasarkan Gambar 4 pada nilai kontinum variabel kinerja yaitu 17176 sesuai dengan data penelitian yaitu termasuk kedalam kategori sangat tinggi, dengan demikian dapat dikatakan bahwa karyawan memiliki kinerja yang tinggi dijalankan pada perusahaan, akan tetapi kinerja pada perusahaan masih perlu ditingkatkan karena semua dimensi berada di bawah skor ideal.
Berdasarkan hasil penelitian dari angket yang disebar kepada 103 responden diketahui bahwa kienrja karyawan PT. Indorama Sycnthetics Tbk. Polyester Division di Purwakarta mencapai skor 17176 dari skor kriterium atau jumlah maksimal perolehan nilai responden terletak pada daerah 18348,8-20909, sehingga dapat dikatakan bahwa dalam penelitian ini kienrja karyawan PT. Indorama Sycnthetics Tbk. Polyester Division di Purwakarta sangat tinggi, namun kinerja tersebut perlu ditingkatkan lagi karena semua dimensi berada dibawah skor ideal.

Berdasarkan penelitian diatas menyatakan bahwa semakin tinggi kemampuan dan lingkungan kerja sosial secara bersama-sama, maka semakin tinggi pula kinerja karyawan PT. Indorama Sycnthetics Tbk. Polyester Division di Purwakarta tersampaikan. Hal ini menunjukkan bahwa semakin baik kemampuan semakin tinggi juga kinerja karyawan PT. Indorama Sycnthetics Tbk. Polyester Division di Purwakarta yang tersampaikan. Selain itu, lingkungan kerja sosial berpengaruh terhadap kinerja karyawan. Hal ini menunjukkan semakin kondusif lingkungan kerja sosial semakin tinggi juga kinerja PT. Indorama Sycnthetics Tbk. Polyester Division di Purwakarta yang tersampaikan.

\section{KESIMPULAN DAN REKOMENDASI}

Berdasarkan hasil penelitian yang telah dilakukan menggunakan analisis deskriptif . Dapat diambil kesimpulan yaitu bahwa kemampuan berada pada kategori sangat baik terlihat dari kemampuan kerja karyawan dalam meningkatkan kinerja perusahaan. Lingkungan kerja sosial berada pada kategori sangat kondusif terlihat dari hubungan kerja yang harmonis antara atasan dan sesama rekan kerja dalam melakukan pekerjaan. Kinerja berada pada kategori sangat tinggi terlihat dari karyawan dalam mengerjakaan pekerjaannya dengan menghasilkan kualitas dan kuantis yang baik dalam mencapai tujuan perusahaan.

Adanya penelitian ini diharapkan dapat membantu peneliti berikutnya dalam melakukan penelitian mengenai kemampuan, lingkungan kerja sosial dan kinerja karyawan dengan menggunkan indikator yang berbeda dari sumber teori yang lebih beragam, dan terhadap objek yang berbeda, karena masih banyaknya keterbatasan dalam penelitian ini, khususnya yang berkaitan dengan metode penelitian dan teknik pengumpulan data.

\section{DAFTAR PUSTAKA}

Albrecht, W. S., Albrecht, C. O., \& Zimbelman, C. C. (2012). Fraud Examination (Fourth Edi). USA: South-Western. 
Ali, M. (2013). Penelitian Kependidikan Prosedur dan Strategi. Bandung: CV Angkasa.

Ali, M. (2013). Penelitian Kependidikan Prosedur dan Strategi. Bandung: CV Angkasa.

Andresen, M., \& Nowak, C. (2015). Human Resource Management Practices Assessing Added Value. Switzerland: Springer.

Anthony, Aeffects. E. (2017). Effects Of Discipline Management On Employee Performance In An Organization: The Case Of County Education Office Human, 2(3), 1-18.

Aprilia, W., \& Hudiwinarsih, G. (2012). Pengaruh Kompensasi, Motivasi dan Komitmen Organisasional Terhadap Kinerja Karyawan Bagian Akuntansi (studi kasus pada perusahaan manufaktur di Surabaya), 2(2), 215-228.

Armstrong, M., \& Taylor, S. (2014). Handbook of Human Resource Management Practice (13th ed.). UK: Kogan Page. http://doi.org/10.1177/030913258901300105

Armstrong, M., \& Taylor, S. (2017). A handbook of human resource management practice. Human Resource Management $(14$ th ed $)$. London: Cogan Page.

Asmaranty, N. (2014). Pengaruh Kompensasi Dan Lingkungan Kerja Terhadap Kinerja Karyawan Divisi Slab Steel Plant II Direktorat Produksi PT Krakatau Steel (Persero) Di Cilegon, 1-23.

Assan, S. Y. M. A. H. (2015). Role Of Human Resource Practices In Employee Performance And Job Satisfaction With Mediating Effect Of Employee Engagement, 53(1), 81-96.

Bagus Kisworo. (2012). PSDM. Semarang: Buku Ajar FIP UNNES.

Bolli, T., \& Farsi, M. (2015). The Dynamics of Productivity in Swiss Universities. Journal of Productivity Analysis, 44(1), 21-38. http://doi.org/doi.org/10.1007/s11123-015-04502

Brasileira, R., Coelho, J. S., Salmaso, C., Universidade, T., \& Coelho, J. S. (2014). Factors associated with work ability in the elderly, (December 2014). http://doi.org/10.1590/18094503201400040003

Burns R. B. (1993). Konsep Diri: Teori, Pengukuran, Perkembangan dan Perilaku. Jakarta: Arcan.

Chen, S., Zhu, X., Welk, G. J., Kim, Y., Lee, J., \& Meier, N. F. (2014). ScienceDirect Using Sensewear armband and diet journal to promote adolescents' energy balance knowledge and motivation. Journal of Sport and Health Science, 3(4), 326-332. http://doi.org/doi.org/10.1016/j.jshs.2013.07.003

Deweese, B. H., Hornsby, G., \& Stone, M. H. (2015). The training process: Planning for strength power training in track and field. Part 2: Practical and applied aspects. Journal of Sport and Health Science, (July). http://doi.org/10.1016/j.jshs.2015.07.002

Emeka, H., Ifeoma, J., \& Emmanuel, I. (2015). The International Journal Of Business \& Management An Evaluation of the Effect of Technological Innovations on Corporate Performance: A Study of Selected Manufacturing Firms in Nigeria Abstract :, 3(1), 248-262.
Emelia, A.-A., \& Darko, T. O. (2017). Leadership, Employee Engagement and Employee Performance in the Public Sector of Ghana. Journal of Business and Management Sciences, 5(2). http://doi.org/10.12691/jbms-5-2-1

García-Pinillos, F., Párraga-Montilla, J. a., SotoHermoso, V. M., \& Latorre-Román, P. a. (2015). Changes in balance ability, power output, and stretch-shortening cycle utilisation after two high-intensity intermittent training protocols in endurance runners. Journal of Sport and Health Science. Retrieved from http://doi.org/10.1016/j.jshs.2015.09.003

Gomez-Mejia, L. R. and D. B. B. and R. L. C. (2012). Managing Human Resources. (I. Pearson Education, Ed.). New York: Prentice Hall.

Jyoti, J., \& Dev, M. (2016). Perceived Highperformance Work System lf-efficacy and Learning Orientation. SAGE, 15(Employee Performance), and Employee Performance. http://doi.org/doi.org/10.1177/09726225166883 92

Khan, A. A., Abbasi, S. O. B. H., Waseem, R. M., Ayaz, M., \& Ijaz, M. (2016). Impact of Training and Development of Employees on Employee Performance through Job Satisfaction: A Study of Telecom Sector of Pakistan. Business Management and Strategy, 7(1), 29-46. http://doi.org/10.5296/bms.v7i1.9024

Kumar, S. (2016). Innovative Motivational Techniques and Their Impact on Performance and Job Satisfaction, 393-397. http://doi.org/doi.org/25.543/jel.v8n1p653

Mahardikawanto. (2013). Pengaruh Lingkungan Kerja Dan Disiplin Kerja Terhadap Kinerja Pegawai.

Masharyono. (2015). Pengaruh Job Characteristics terhadap Semangat Kerja Pegawai (Survey pada Pegawai PNS di Lingkungan Disparbud Jabar), 3(3), 813-830.

Masharyono, Sumiyati, T. (2016). Physical Work Environment Effect on Employee Productivity of Textile Industry. Advances in Economics, Business and Management Research, 15, 630632.

Mathis, R. L., \& Jackson, J. H. (2011). Human Resource Management (13th ed.). United States of America: Cengage Learning.

Mathews, C., \& Khann, I. K. (2016). Impact of Work Environment on Performance of Employees in Manufacturing Sector in India: Literature Review, 5(4), 2013-2016.

Moeheriono. (2010). Pengukuran Kinerja Berbasis Kompetensi. Surabaya: Ghalia Indonesia.

Mondy, R. W., \& Martocchio, J. J. (2016). Human Resource Management (14th ed.). United States of America: Pearson.

Muda, I., Rafiki, A., \& Harahap, M. R. (2014). Factors Influencing Employees' Performance: A Study on the Islamic Banks in Islamic Science University of Malaysia University of North Sumatera. International Journal of Business and Social Sience, 5(2), 73-81.

Nitisemito, A. S. (2003). Manajemen Personalia (Kedua). Jakarta: Ghalia Indonesia.

Nuryanti, B. L., \& Rahmawati, R. (2016). The Influence of Situational Leadership and Work 
Environment towards Employees 'Performance, $15,540-543$.

Odunlami, I. B., \& Matthew, A. O. (2014). Compensation Management and Employees Performance in the Manufacturing Sector, A Case Study of a Reputable Organization in the Food and Beverage Industry. International Journal of Managerial Studies and Research, 2(9), 108-117.

Osa, I. G. (2014). Monetary Incentives Motivates Employee's On Organizational Performance. Global Journal of Arts Humanities and Social Sciences, 2(7).

Ritonga, S. K. (2013). Sistem Informasi Penilaian Kinerja Karyawan Menggunakan Metode Technique For Others Reference By Similarity To Ideal Solution (TOPSIS), 142-147.

Rivai, V., \& Sagala, E. J. (2013). Manajemen Sumber Daya Manusia untuk Perusahaan dari Teori ke Praktik (Edisi Kedu). Jakarta: Rajawali Pers.

Rivai, Veitzhal, \& Sagala, E. J. (2014). Manajemen Sumber Daya Manusia Untuk Perusahaan Dari Teori Ke Praktik. Jakarta: Rajawali Pers.

Robbins, Stephen P \& Judge, T. A. (2013). Organizational Behavior. (Pearson Education, Ed.) (15th ed.). New Jersey.

Saari, L. M., \& Judge, T. A. (2014). Employee Attitudes and Job Satisfaction. IJHSS, 43(4), 395-407. http://doi.org/doi.org/10.1002/hrm.20032

Sajid, H. (2017). Impact of organizational politics on employee performance in public sector organizations.

Schaefer, C. P., Cappelleri, J. C., Cheng, R., Cole, J. C., Guenthner, S., Fowler, J., ... Mamolo, C. (2015). Health care resource use, productivity, and costs among patients with moderate to severe plaque psoriasis in the United States. Journal of the American Academy of Dermatology, 74(4), 585-593. Retrieved from http://doi.org/10.1016/j.jaad.2015.06.049

Sedarmayanti. (2007). Sumber Daya Manusia dan Produktivitas Kerja. Bandung: Penerbit Mandar Maju.

Sedarmayanti. (2011). Tata Kerja dan Produktivitas Kerja: Suatu Tinjauan Dari Aspek Ergonomi Atau Kaitan Antara Manusia Dengan Lingkungan Kerjanya (Ketiga). Bandung: Mandar Maju.

Senen, S. H., Sumiyati, \& Masharyono. (2017). Employee Performance Assessment System Design Based on Competence, 2, 68-70.

Senen, S. H., \& Triananda, N. (2016). The Employee Performance Influenced by Communication: a Study of BUMD in Indonesia, 15, 596-598.

Senen, S. H., \& Wahyuni, Y. (2016). Pengaruh gaya kepemimpinan dan budaya organisasi terhadap kinerja karyawan pt sugih instrumendo abadi di padalarang, $1(2)$, 59-69.

Sigit, S. (2003). Esensi Perilaku Organisasi. Yogyakarta: Lukman Offset.

Siramiati Ni Wayan; Surachman, H. D. R. F. (2016). Performance Based Compensation Effect On Employee Motivation Satisfaction Of Employees And Performance Of Employees (Study On Private Universities In The Province
Of Bali Conceptual. International Journal of Business, Economics, and Law, 11(2), 62-70.

Sumiyati, Masharyono, Purnama, R., \& Pratama, K. F. (2016). The Influence of Social Work Environment on Employee Productivity in Manufacturing in Indonesia, 15, 649-652.

Sunyoto, D. (2012). Manajemen Sumber Daya Manusia. Yogyakarta.

Supriyani, \& Mahmud. (2013). Membangun Kinerja Karyawan Melalui Motivasi Kerja, Kepuasan Kerja Dan Komitmen Organisasi Pada PT. Astra Internasional Di Semarang, (2011).

Sutermeister, R. A. (1976). People abd Productivity. New York: McGraw - Hill Inc.

Thoha, M. (2010). Kepemimpinan dan Manajemen. Jakarta: PT. Raja Grafindo Persada.

Torang, S. (2012). Perilaku Organisasi. Bandung: Alfabeta.

Tran, L., \& Thao, T. (2015). Factors Affecting Employee Performance - Evidence From Petrovietnam Engineering.

Tummers, L. (2017). The Relationship Between Coping And Job Perfomance. Journal Of Public Administration Research And Theory.

Wardhana, R. M. D. H. ., Tarmedi, E., \& Sumiyati. (2016). Upaya meningkatkan kinerja dengan cara memberikan motivasi kerja dan menumbuhkan komitmen organisasional pegawai dinas perhubungan provinsi jawa barat. Journal of Business and Management Education, 1(2), 91-96.

Wibowo. (2014). Manajemen Kinerja. Jakarta: Rajawali.

Yukl, G. (2010). Kepemimpinan dalam Organisasi (kelima). Jakarta: PT. Indeks.

Zachary, L. (2017). Creating a Mentoring Culture The Organization Guide (John Wille). San Fransisco: John Wiley \& Sons Inc. http://doi.org/doi.org/6583-12 